\title{
ON THE COVER
}

\section{Eleventh Avenue Walkers/Good Dogs by Jacquie Green}

\author{
Portions of the following are based on an interview with \\ the artist on December 13, 2017.
}

In an often-referenced quote, the late Robert Kennedy commented: "There are those that look at things the way they are, and ask why? I dream of things that never were, and ask why not?" Artist Jacquie Green, whose Eleventh Avenue Walkers/Good Dogs serves as this month's cover art, is driven by this kind of challenge, whether in relation to society in general or her art methods in particular.

Green grew up in Toronto, Ontario, Canada, where she still resides. As a teacher, she was assigned an "ideal job," creating a curriculum for academically gifted students. She reflects that at that point she was a "word-based person." When a visual artist came to work with her students for a 10-day intensive and she could observe non-language-based learning, she was intrigued. She recognized that students use different styles to learn, yet "I couldn't imagine how you could process the world without words, how you could convey or analyze without words."

That conundrum led Green to the Ontario College of Art and Design to learn more about how art teachers taught. She got "hooked," taking more and more classes there. When the Board of Education cut funding for her program at about the same time as she graduated with a new arts degree, Green felt she had "space in all ways" to develop a visual arts practice. That was 25 years ago.

"I am a question asker," Green says. "I like to look at things out of the context that people normally do. I like to ask: Really?! I see questions where people see givens." Taking something out of context allows her to "examine it in a way that reveals tensions, surprises, even funny aspects of the world around me. I like to make it arresting, so that the viewer will see something new in their everyday world."

The two paintings, Eleventh Avenue Walkers and Good Dogs, are part of a series of paintings of dog walkers. This series, Tamed, explores the relationship between human beings and the animals that are an integral part of their worlds. The series also speaks to questions Green feels have been insufficiently examined. She asks,

What happens to people-men in particular-when work is not available to them anymore. "I am a lawyer, a doctor." "No, you're a human being. You work as a lawyer." What will happen to them? That's why I often portray men off balance, out of context, and incomplete. This disruption hasn't been discussed-but it needs to be.

Green manifests this disruption in various ways, such as by cropping images or flattening the plane through use of a white, blank background. A pack of dogs approaches, yet we do not experience them as scary or dangerous. Why not? Because of the person and the leash. Green notes, then, that the containment is a function of power-the power relationship between human and animal. (Green herself owns a tiny goldendoodle. She describes it as the least scary dog in the world, "like a wind-up toy.") Implicit as well are the myriad questions related to people hired to walk dogs in our society.

Green's mixed method is one that she has developed as a way to challenge herself, to keep things from being too easy for her. She starts out with a drawing, an image. On a wooden panel, she then creates a collage from various print material, whether magazines or old books, and rips them up into interesting shapes. For the dog paintings, she referenced fur and the wet dog smell, as well as various relevant quotations. Once the collage feels complete, she uses a steel nib pen-she notes that it is the same kind of steel nib pen that Jane Austen used-and permanent ink to draw the image onto the collage. Using a steel nib pen means that the line will not be smooth: The unpredictable variation in the lines created by this instrument may well interrupt the fluidity of the drawing. The drawings "have an almost jerky quality that I make myself do by making it more difficult for me. Drawing can flow too easily; it then loses its interest both for the artist and viewer."

Green experiences the painting as a "battle" between the collage and the pen and ink. Once the ink becomes stronger than the collage, Green masks out all the rest of the collage with white paint. With the image vivid against the nothingness of the white, the background - the paper underneathnow becomes textured and adds vibrancy and movement to the painting.

Ever conscious of the differences between the verbal and the visual worlds, Green notes that with visual art, "the whole thing hits you in an instant, rather than being timebased. If I have a specific message, then I write. If I want to raise a question-that's what painting does."

Kate F. Hays, Art Co-Editor 